\title{
Cystic Neoplasms of the Pancreas
}

\author{
Anne Marie Lennon • Christopher Wolfgang
}

Received: 16 October 2012 / Accepted: 26 October 2012 /Published online: 24 January 2013

(C) 2013 The Society for Surgery of the Alimentary Tract

\begin{abstract}
Pancreatic cysts are being identified with increasing frequency due to a combination of increased awareness and more frequent use of cross sectional imaging. Cystic neoplasms of the pancreas range from completely benign to frankly malignant. Identifying pre-malignant cysts offers the opportunity to prevent the development of pancreatic cancer. This article reviews the presentation, workup, and non-operative and operative management of premalignant and malignant pancreatic cysts.
\end{abstract}

Keywords IPMN $\cdot$ MCN $\cdot$ Pancreatic cyst $\cdot$ Intraductal papillary mucinous neoplasm $\cdot$ Serous cystadenoma $\cdot$ Solid pseudopapillary tumor $\cdot$ Pancreatic cancer $\cdot$ Cyst

\begin{tabular}{|c|c|}
\hline \multicolumn{2}{|c|}{ Abbreviations } \\
\hline $\mathrm{CT}$ & Computer axial tomography \\
\hline EUS & Endoscopic ultrasound \\
\hline EUS-FNA & $\begin{array}{l}\text { Endoscopic ultrasound with fine } \\
\text { needle aspiration }\end{array}$ \\
\hline IPMN & $\begin{array}{l}\text { Intraductal papillary mucinous } \\
\text { neoplasm }\end{array}$ \\
\hline BD-IPMN & Branch duct IPMN \\
\hline MD-IPMN & Main duct IPMN \\
\hline MEN & Multiple endocrine neoplasia \\
\hline MRI & Magnetic resonance imaging \\
\hline $\mathrm{MCN}$ & Mucinous cystic neoplasm \\
\hline MCA & Mucinous cystadenocarcinoma \\
\hline MPD & Main pancreatic duct \\
\hline PanNET & Pancreatic neuroendocrine tumor \\
\hline PDAC & Pancreatic ductal adenocarcinoma \\
\hline SCA & Serous cyst adenoma \\
\hline SCAC & Serous cystadenocarcinoma \\
\hline SPT & Solid pseudopapillary tumor \\
\hline VHL & Von Hippel Lindau \\
\hline
\end{tabular}

A. M. Lennon $\cdot$ C. Wolfgang $(\triangle)$

The Johns Hopkins Hospital,

Baltimore, MD, USA

e-mail: cwolfga2@jhmi.edu

A. M. Lennon

e-mail: amlennon@jhmi.edu

\section{Introduction}

Neoplastic cysts of the pancreas were previously thought to be a rare condition, being identified on $0.2 \%$ of transabdominal ultrasounds. ${ }^{1}$ With the increased use of crosssectional imaging and improvements in these technologies, pancreatic cysts have now become one of the more common gastrointestinal disorders. One contemporary study has reported that the prevalence of incidental pancreatic cysts identified on multi-detector computer tomography (CT) scans is $2.6 \%$. $^{2}$ The prevalence of incidental pancreatic cysts identified on magnetic resonance imaging (MRI) is generally higher than CT and ranges from $2.4^{3}$ to $13.5 \%$. Interestingly, radiologists often fail to document pancreatic cysts, with $69 \%$ of cysts not being reported in the original radiology report suggesting that these lesions are under diagnosed. ${ }^{4}$ Surgical series also demonstrate a rising prevalence of incidentally detected pancreatic cysts which has increased by $28 \%$ over the 33 years. $^{5}$

Cystic neoplasms of the pancreas are a biologically heterogeneous group of tumors that range from completely benign to frankly malignant. As such, these lesions pose a significant management challenge. The care of these patients requires balancing the risk of an unnecessary pancreatectomy that is associated with significant mortality and morbidity with missing or preventing a potentially curative malignancy. The presumptive classification of the cyst on clinical grounds is important for subsequent management. Guidelines for the management of pancreatic cysts exist. ${ }^{6}$ Ongoing studies, including the genetic characterization of 
cystic neoplasms of the pancreas, hold the promise for improvements in future management paradigms. The goals of this review is to provide an overview of the most commonly identified cystic neoplasms of the pancreas and to present a general guideline for their management based on the available literature and consensus guidelines.

\section{Classification of Pancreatic Cysts}

Pancreatic cysts can be broadly divided into inflammatory and neoplastic cysts. Inflammatory cysts, also known as pseudocysts, are the sequelae of pancreatitis and have no malignant potential and will not be discussed further. Neoplastic cysts are classified based on the type of fluid they produce into non-mucinous and mucinous cysts (Fig. 1). Non-mucinous cysts include a primarily cystic lesion called a serous cystadenoma (SCA) and several primarily solid lesions that undergo cystic degeneration. The vast majority of the latter category consists of cystic pancreatic neuroendocrine tumor (PanNET) and solid pseudopapillary neoplasms (SPN). Pancreatic adenocarcinoma rarely degenerates into a cystic lesion but may be associated with a mucinous pancreatic cyst. Mucin-producing cystic neoplasms are precursor lesions to invasive pancreatic cancer (i.e., pancreatic adenocarcinoma/ductal adenocarcinoma) and are comprised of the relatively uncommon mucinous cystic neoplasms (MCN) and the more common intraductal papillary mucinous neoplasms (IPMN). Finally, very rare cystic lesions exist and include lymphoepithelial cysts, acinar cell cystadenoma and cystadenocarcinoma, cystic teratoma, choriocarcinoma, and angiomatous neoplasms. In a large retrospective study of resected pancreatic cysts, IPMN were the most commonly resected cyst accounting for $23.6 \%$ of cases, $23.4 \%$ were MCN, while PanNET accounted for $7.3 \%$, SPN for $3.4 \%$, with cystic degeneration of ductal adenocarcinoma accounting for $0.8 \% .5$

\section{Symptoms}

With the advent of frequent cross-sectional imaging in the workup of numerous abdominal complaints, the most common presentation of a pancreatic cyst has changed over the years. Currently, the most common presentation is the incidental finding of an asymptomatic cyst. ${ }^{5}$ In patients who present with symptoms, the complaints are often nonspecific such as nausea, vomiting, or vague abdominal pain. ${ }^{5,7,8}$ Symptoms that are directly attributable to the cyst include jaundice, acute pancreatitis, abdominal pain, back

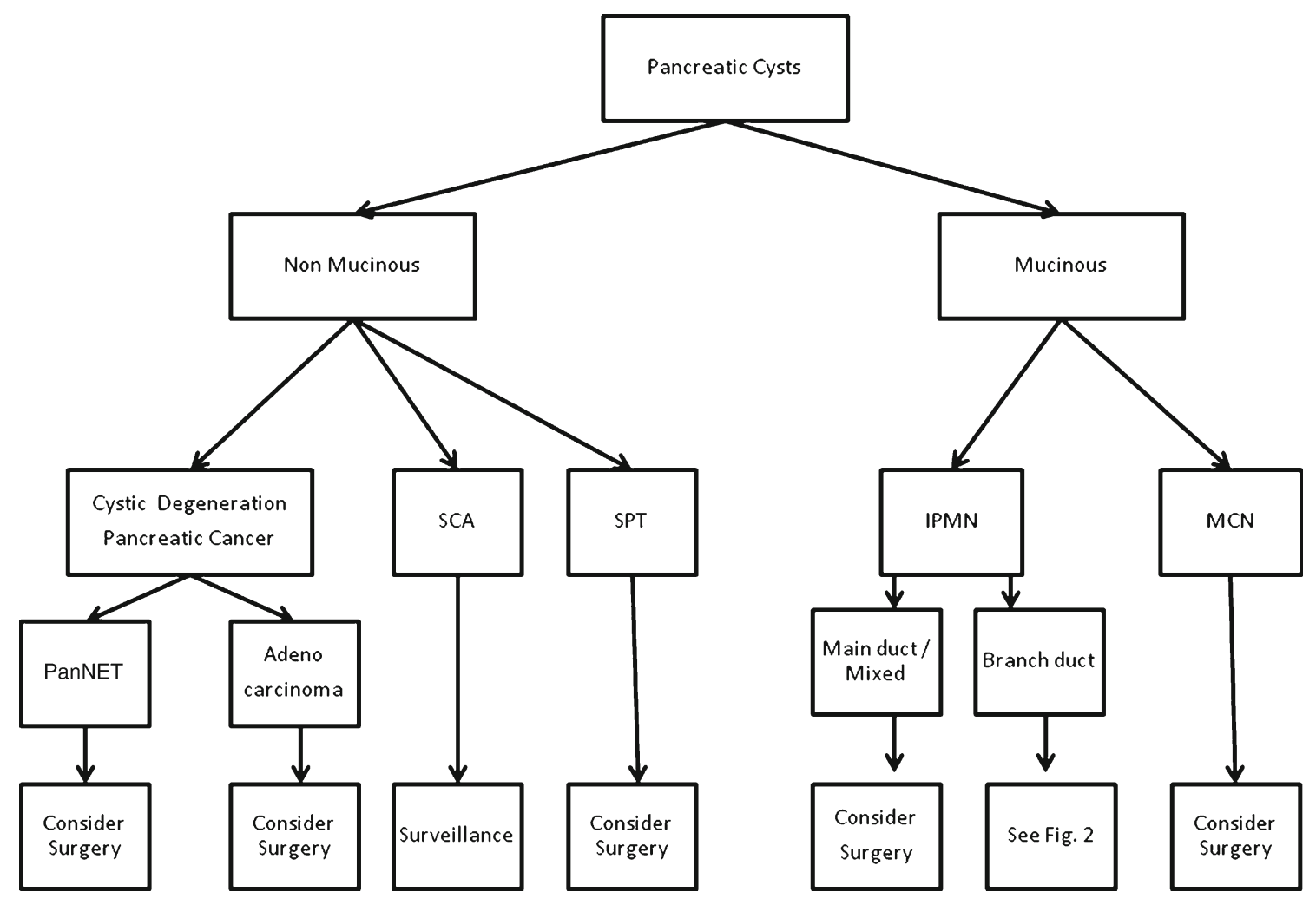

Fig. 1 Algorithm for the management of mucinous and non-mucinous pancreatic cysts 
pain, steatorrhea, and weight loss $^{9}$ (Table 1). Jaundice, significant weight loss, and pain are associated with a high risk of malignancy in certain cyst types.

\section{Diagnosis}

The diagnosis of a pancreatic cyst is most often made by $\mathrm{CT}$ or MRI either performed for symptoms caused by the lesion or by another condition. The management of an individual with the finding of a pancreatic cyst is dependent on a presumptive diagnosis of cyst type. Determination of this presumptive diagnosis is based on clinical factors such as gender, age of presentation, and cyst characteristics as determined by imaging modalities and cyst fluid analysis. Although this paradigm is never completely accurate in distinguishing among cyst types, it is correct the majority of the time. With this limitation in mind, all patients can be managed safely.
Several factors can be used to help determine the etiology of a pancreatic cyst (Table 1). These factors are divided into patient demographics/history, imaging characteristic, and cyst fluid analysis. With regards to demographics, the affected patient population is distinct for the various cyst types. The commonly found IPMN have age and gender distribution similar to that of pancreatic adenocarcinoma albeit the median age of presentation in several years younger consistent with their precursor status. The less common MCNs are almost always found in middle-aged females. A recent multicenter study found that $98.1 \%$ of MCN occurred in females with a mean age of $48.1 .{ }^{10} \mathrm{SCA}$ are also seen predominately in women but to a much lower degree with a male to female ratio of $30: 70{ }^{11}$ The gender distribution of SPN is similar to that of MCNs in that over $89 \%$ of SPN occur in women, ${ }^{12-14}$ making this diagnosis far less likely in men. SPN classically occur in young women, with a median age of 21-33, much younger than that of SCA or MCN ${ }^{5,14}$ Cystic PanNET follow the demographics of their

Table 1 Features of neoplastic pancreatic cysts

\begin{tabular}{|c|c|c|c|c|c|}
\hline Pancreatic cyst & $\mathrm{SCA}^{5,7,14,16,28,29}$ & IPMN $^{5}$ & & $\mathrm{MCN}^{5,6,8,10}$ & $\mathrm{SPN}^{5,13}$ \\
\hline Sex (female, \%) & $68-80.7$ & $50-57$ & & $84-98.1$ & $88-91$ \\
\hline Mean age & $60-61$ & 69 & & $45-51$ & $21-33$ \\
\hline Symptoms (\%) & $19.8-64$ & $52-65$ & & $48.6-84$ & 89.5 \\
\hline Abdominal pain (\%) & $12-47$ & $51-64$ & & $52-60$ & 46.5 \\
\hline Acute pancreatitis (\%) & $0.9-4$ & $12-23$ & & $9.2-10$ & 0 \\
\hline Weight loss (\%) & $0-14$ & $20-44$ & & $11.7-21$ & 0.93 \\
\hline Nausea/vomiting (\%) & $1-6$ & $2-21$ & & 43 & 7.1 \\
\hline Jaundice (\%) & $1-7$ & $7-33$ & & 0 & 1.09 \\
\hline \multicolumn{6}{|l|}{ Location } \\
\hline Head/uncinate (\%) & $37-44$ & $58-71.7$ & & $0.6-26.1$ & $31-34$ \\
\hline Body or tail (\%) & $53-61$ & $30.6-37$ & & $67.3-99.4$ & $61-69$ \\
\hline Mean size $(\mathrm{cm})$ & $4.1-5.1$ & $2.9-2.9$ & & $4.4-5.0$ & $4.1-6.1$ \\
\hline Multiple (\%) & $\mathrm{No}^{\mathrm{a}}$ & $20-25$ & & No & No \\
\hline \multirow[t]{6}{*}{ Appearance } & & MD-IPMN & BD-IPMN & & \\
\hline & $58 \%$ microcystic & MPD $>5 \mathrm{~mm}$ & \multirow{5}{*}{$\begin{array}{l}\text { Dilated side branches } \\
>5 \mathrm{~mm} \text { in communication } \\
\text { with MPD }\end{array}$} & Unilocular cyst & $\begin{array}{l}\text { Cystic and solid } \\
\text { appearance }\end{array}$ \\
\hline & $20 \%$ macrocystic & \multirow[t]{4}{*}{$\begin{array}{l}\text { Mixed: dilation MPD> } \\
5 \mathrm{~mm} \text { and side branches }\end{array}$} & & $\begin{array}{l}\text { Calcification around } \\
\text { edge of the cyst }\end{array}$ & \multirow[t]{4}{*}{$\begin{array}{l}\text { No communication } \\
\text { with MPD }\end{array}$} \\
\hline & $\begin{array}{l}16 \% \text { mixed } \\
3 \% \text { solid }\end{array}$ & & & \multirow[t]{3}{*}{$\begin{array}{l}\text { Classically no communication } \\
\text { seen with MPD }\end{array}$} & \\
\hline & $30 \%$ central calcification & & & & \\
\hline & $\begin{array}{l}\text { Classically no } \\
\text { communication seen } \\
\text { with MPD }\end{array}$ & & & & \\
\hline Cyst fluid CEA & Low & High & & High & Not applicable \\
\hline Cyst fluid cytology & $\begin{array}{l}\text { Cuboidal glycogen- } \\
\text { staining cells }\end{array}$ & $\begin{array}{l}\text { Mucin-containing } \\
\text { columnar cells; atypia }\end{array}$ & & $\begin{array}{l}\text { Mucin-containing columnar } \\
\text { cells; small papillary sheets; } \\
\text { atypia }\end{array}$ & $\begin{array}{l}\text { Branching papillae } \\
\text { with myxoid } \\
\text { stroma }\end{array}$ \\
\hline
\end{tabular}

${ }^{a}$ Unless associated with Von Hippel Lindau syndrome

$M P D$ main pancreatic duct, IPMN intraductal papillary mucinous neoplasm, $B D-I P M N$ branch duct IPMN, $M D-I P M N$ main duct IPMN, $M C N$ mucinous cystic neoplasm, $S C A$ serous cystadenoma, $S P N$ solid pseudopapillary tumor 
solid counterparts. Other factors in the past medical history may give further clues as the cyst type. A personal history of pituitary and thyroid adenoma should raise the possibility of multiple endocrine neoplasia (MEN) 1 which is associated with PanNET. SCA are most often sporadic but can be seen in patients with Von Hippel Lindau syndrome which is a rare, autosomal dominant disease, associated with a constellation of conditions including hemangioblastomas, retinal angiomas, clear cell renal carcinomas, and pheochromocytoma.

The findings on imaging are also very useful in discriminating among the various cyst types (Table 1). Important parameters to assess include the number of cysts, enhancement pattern, morphology, and relationship with the pancreatic duct. IPMN are found throughout the gland with 20 to $25 \%$ being multifocal whereas over $95 \%$ of MCN occur in the body or tail of the pancreas and are essentially never multifocal. ${ }^{9,10}$ Similarly, SCA and SPN are most often found as isolated lesions. Cystic PanNET are similarly isolated lesions but can be multifocal in patients with MEN I.

In addition to location, the appearance on CT or MRI is also important. All neoplastic cysts have at least a portion of the tumor that enhances with fluid density consistent with their cystic nature. Simple thin-walled cysts are comprised essentially of mainly cyst fluid, and the enhancement pattern of the wall may be hard to assess. In cysts with thicker walls, the enhancement pattern can often be evaluated. For mucin producing tumors, enhancement is isodense or hypodense on venous phase. Nodularity of the wall is considered to be a solid component or mural nodule. The wall of a cystic Pan-NET often enhances on arterial phase unlike IPMN, MCN, SPN, and SCA that have an isodense wall in this phase.

The morphology of cysts on imaging is also important in differentiating among the various types. Main duct IPMNs (MD-IPMN) are characterized by a diffuse dilatation of the main pancreatic duct in the absence of a prominent cyst. Dilatation of the main pancreatic duct in conjunction with at least one pancreatic cyst is considered to be a mixed type IPMN. Side-branch (SB-IPMN) and mixed type IPMN are usually multiloculated lesions that can be thought of as mimicking a cluster of grapes. This is in contrast to SCA in which approximately $58 \%$ have a classic microcystic morphology ${ }^{8,15}$ (Fig. 2) that is similar to the appearance of a sliced orange. It should be noted that $20 \%$ of SCA are macrocystic which are virtually identical in appearance to MCN (Fig. 3). Sixteen percent mixed micro- and macrocystic, while $3 \%$ had a solid appearance mimicking a PanNET or cystic adenocarcinoma. ${ }^{8}$

MCN and cystic PanNETs most often have very few septations and are spherical. The appearance of SPN is characterized by both solid and cystic components. IPMN are seldom found in association with a calcification while $25 \%$ of SCA have a characteristic calcification within the center of the cyst that is considered virtually pathognomonic. ${ }^{16}$ Peripheral calcification can occur in both MCN and SPN.

Communication with the pancreatic ductal system is also useful in differentiating the various cysts. This communication is probably best visualised with MRI-IPMN communicate with the pancreatic ductal system, whereas MCN, SCA, SPN, and cystic PanNET do not. This feature has been used in many studies to define BD-IPMN or mixed IPMN. ${ }^{6,16}$

Endoscopic ultrasound (EUS) provides useful additional information to cross-sectional imaging. When performed by an experienced gastroenterologist, this modality is highly sensitive in determining the presence of a solid component and the relationship to the pancreatic ductal system. Moreover, EUS allows for fine needle aspiration (FNA) of the pancreatic cyst. The cyst fluid can be analyzed for CEA, amylase, cytology, and molecular markers. A multicenter study found that elevated cyst fluid CEA was superior to either EUS morphology or cytology with a cutoff of $192 \mathrm{ng} / \mathrm{mL}$ associated with a $79 \%$ sensitivity and $84 \%$ specificity for identifying mucinous cysts. ${ }^{17}$ A low CEA of $<5 \mathrm{ng} / \mathrm{mL}$ has a $50 \%$ sensitivity and $95 \%$ specificity for the identification of a SCA or pseudocyst. ${ }^{18}$ Cyst fluid amylase is elevated if there is communication between the cyst and the main pancreatic duct with a very low amylase $(<250 \mathrm{IU} / \mathrm{L})$ associated with a $98 \%$ specificity for pseudocyst. In a large, prospective multicenter trial, cytology had a high specificity ( $83 \%$ ) but low sensitivity (35\%) for identifying mucinous cysts. ${ }^{17}$ However, it has a higher sensitivity and specificity of $88 \%$ and $96 \%$, respectively, for detecting cystadenocarcinoma. ${ }^{19}$

\section{Risk of Malignant Transformation and Treatment}

The management of pancreatic cysts is determined by the etiology of the cyst and the risk of malignant transformation (Fig. 1).

\section{Serous Cystadenoma}

The risk of malignant transformation of SCA is extremely low, with four large studies collectively representing a total of 693 patients reporting a risk of serous cystadenocarcinoma (SCAC) ranging between 0 and $1.2 \%{ }^{8,11,20,21}$ Aside from the development of SCAC, there is a small risk of patients developing what has been termed a "locally aggressive" SCA, and there may be a slight increased risk of malignancy in this subset. The largest series on this topic reported the risk of aggressive behavior, defined as local invasion, to occur in $5.1 \%$ of patients undergoing resection 
Fig. 2 Classic appearance of a microcystic serous cystadenoma. a EUS image showing the classical microcystic appearance. b CT of the same patient. c 3D reconstruction showing the blood vessel draped over the cyst. (CT images courtesy of Dr. E. Fishman)

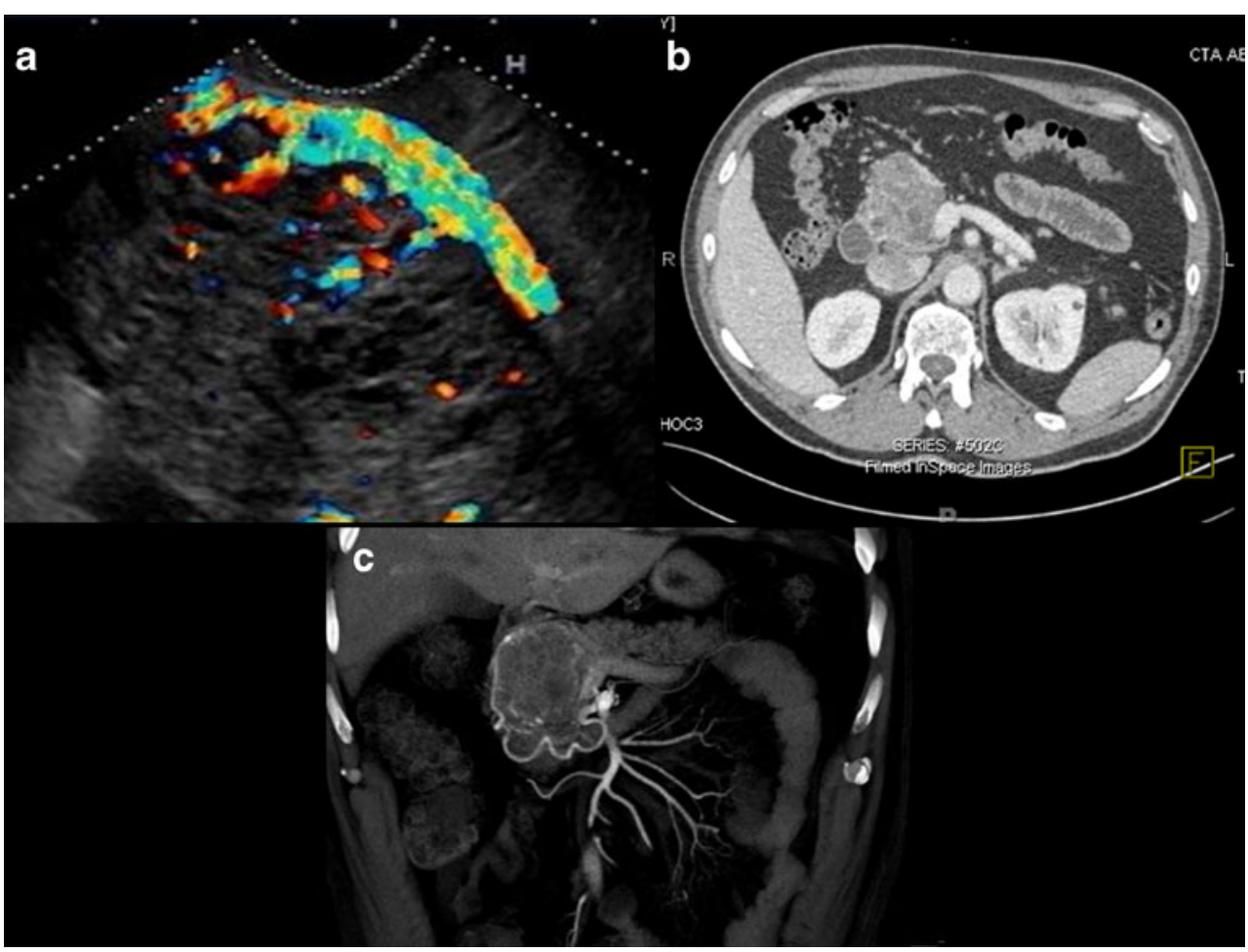

of SCA. ${ }^{11}$ One of the 13 patients with local invasion subsequently developed SCAC with liver metastases.

Based on the low risk of malignancy of SCA, surgical resection should only be considered when the cysts are causing symptoms or when differentiation from a mucinous cystic neoplasm with concerning features is not possible. ${ }^{21,22}$ This is also the recommendation of the American College of
Gastroenterology guidelines. ${ }^{22}$ It should be noted that some authors have proposed that SCA greater than $4 \mathrm{~cm}$ should be considered for resection based on the premise they may grow and become unresectable or degenerate into a malignancy ${ }^{21,23}$ however this is approach controversial.

For patients who do not undergo resection, there are no guidelines for how often they should undergo surveillance.
Fig. 3 Macrocystic serous cystadenoma. These images show four different examples of macrocystic SCA

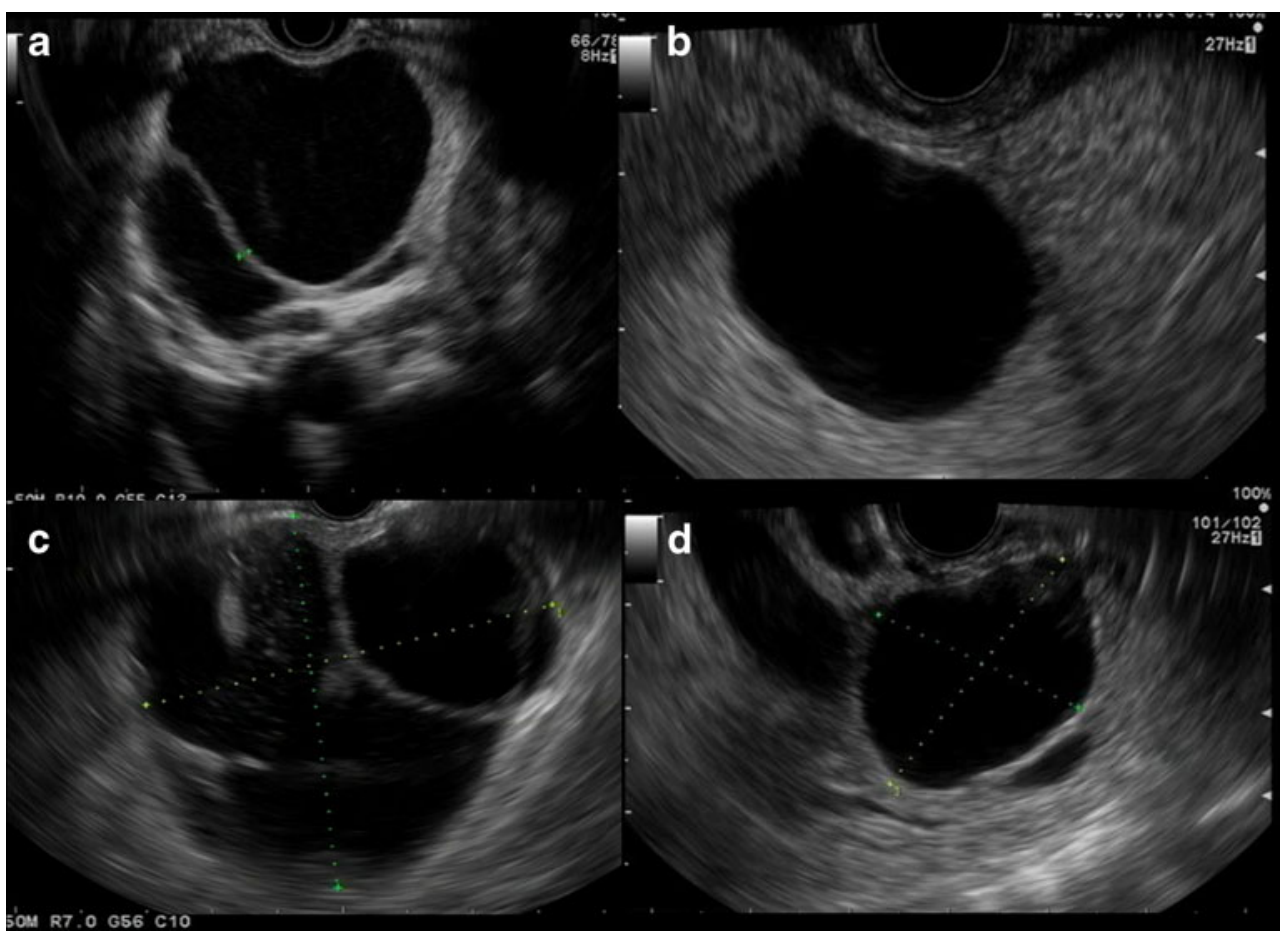


A recent study has assessed the rate of growth of SCA in 145 patients. ${ }^{15}$ The rate of growth was found to be smaller $(0.1 \mathrm{~cm} /$ year $)$ in the first 7 years compared to the subsequent period $(0.6 \mathrm{~cm} /$ year $) .{ }^{15}$ More rapid tumor growth was associated with macrocystic SCA and increased age. Our protocol at Johns Hopkins is for yearly cross-sectional imaging on presumed SCA.

\section{IPMN}

The risk of malignancy of IPMNs is related to the involvement of the main pancreatic duct. Main duct IPMN (MDIPMN) are defined as having segmental or diffuse dilation of the main pancreatic duct to $>5 \mathrm{~mm}$ in the absence of a dominant cyst. Branch duct IPMN (BD-IPMN) are defined as an IPMN with at least one cysts measuring $>5 \mathrm{~mm}$ in diameter in the presence of a normal or minimally dilated pancreatic duct. A mixed type IPMN has either one or more dominant cysts in combinations with a pancreatic duct measuring $>5 \mathrm{~mm}$. This classification scheme has important clinical implications since the risk of malignancy is relatively high in both main duct and mixed types. MD-duct or mixed IPMN is associated with 62.2 and $57.6 \%$ high-grade dysplasia and 43.6 and $45.3 \%$ invasive cancer, respectively. ${ }^{6} \mathrm{BD}-\mathrm{IPMN}$ is associated with a lower risk of 24.4 and $16.6 \%$, respectively. ${ }^{6}$

Surgical resection should be considered in all patients with main pancreatic ductal (Fig. 4). In contrast, BDIPMN has a much lower risk of malignant transformation, with an annual rate of 2 to $3 \%{ }^{24,25}$ Surgery is recommended in patients with obstructive jaundice due to the cyst or where there is a solid component within the cyst. Patients whose cyst measures $>3 \mathrm{~cm}$, where the cyst walls are thickened or enhancing, the main pancreatic duct measured between 5 and $9 \mathrm{~mm}$, where there is an abrupt change in caliber of the pancreatic duct with distal pancreatic atrophy, there is a non-enhancing mural nodule or those who are symptomatic should undergo EUS. Patients who are found to have a mural nodule, main duct suspicious for involvement, or cytology suspicious or positive for malignancy should be considered for surgical resection. ${ }^{6}$ All BDIPMN who do not fulfill these criteria should undergo surveillance, the timing of which is determined by cyst size (Fig. 4). In prior guidelines, cyst size $>3 \mathrm{~cm}$ was considered an indication for resection; however, in the most recent guidelines published earlier this year, BD-IPMN $>3 \mathrm{~cm}$ without any suspicious features can be observed, particularly if elderly.

IPMN recurs in up to $20 \%$ of patients following resection. ${ }^{6}$ Postoperatively, patients with cysts in the remnant pancreas should be followed as per BD-IPMN protocol (Fig. 4). Those without cysts and with negative margins (including those with PanIN-1A or 1B) can undergo surveillance at 2 and 5 years. ${ }^{6}$ Patients with low- or moderate-grade dysplasia at the margin and no invasive component should undergo clinical review and MRCP twice a year is asymptomatic. Those with invasive disease should be followed as per pancreatic ductal adenocarcinoma protocol. $^{6}$

\section{MCN}

Prior studies had suggested that MCN had a high risk of malignant transformation with a risk of invasive mucinous cystadenocarcinoma of $44 \%$ reported in one study of 32 patients. ${ }^{26}$ More recent studies have found a lower association of malignant transformation. A recent multicenter study from the Japanese Pancreas Society of 156 patients with surgically resected MCN found that $13.4 \%$ had high-grade dysplasia, with only $3.9 \%$ having invasive cancer. ${ }^{10} \mathrm{~A}$ joint study in 163 individuals from the Massachusetts General Hospital and the University of Verona found HGD in 5.5\% and invasive carcinoma in $12 \% .{ }^{9}$ One reason for the difference between the older and newer studies is that several of the older studies did not require the presence of ovarian stroma as a prerequisite for the diagnosis of MCN thus likely including side branch IPMN. ${ }^{27-29}$ The size of the cysts in the more recent studies is also smaller (mean $5.5^{7}$ versus $10.5 \mathrm{~cm}^{30}$ ) with studies showing no malignancy in MCNs which measure less than $4 \mathrm{~cm}$ without mural nodules. ${ }^{7,9}$

Surgical resection is recommended for all surgically fit patients with MCN based on the rationale that the natural history of this disease is unknown and that the majority of the patients are young and will require years of follow-up with cross-sectional imaging. ${ }^{6,22}$ In patients who are older, or frail, observation may be considered. ${ }^{6}$

The survival of patients with low, moderate, or high dysplasia in MCN is excellent with $100 \% 5$-year diseasespecific survival in two large studies. ${ }^{9}$ Survival for those with invasive disease is far lower with 5 -year survival of between 0 and $57 \% .{ }^{9}{ }^{10}$ Given these findings, only patients with invasive $\mathrm{MCN}$ require postoperative follow-up imaging, which should match that of PDAC. Patients with MCN and no evidence of invasive disease do not require postoperative surveillance. ${ }^{6}$

\section{SPN}

Solid pseudopapillary neoplasms are considered low-grade malignant neoplasm with the potential for metastatic spread, and surgical resection is therefore recommended in all patients. ${ }^{14}$ Long-term prognosis is excellent in patients who undergo surgical resection with 5-year survival of $95 \% .{ }^{14}$ Even in patients with metastatic diseases, prognosis remains good with only $18.2 \%$ of patients with metastases dying with a mean follow-up of 6.3 years (range 1-16). ${ }^{31}$ Postoperative 


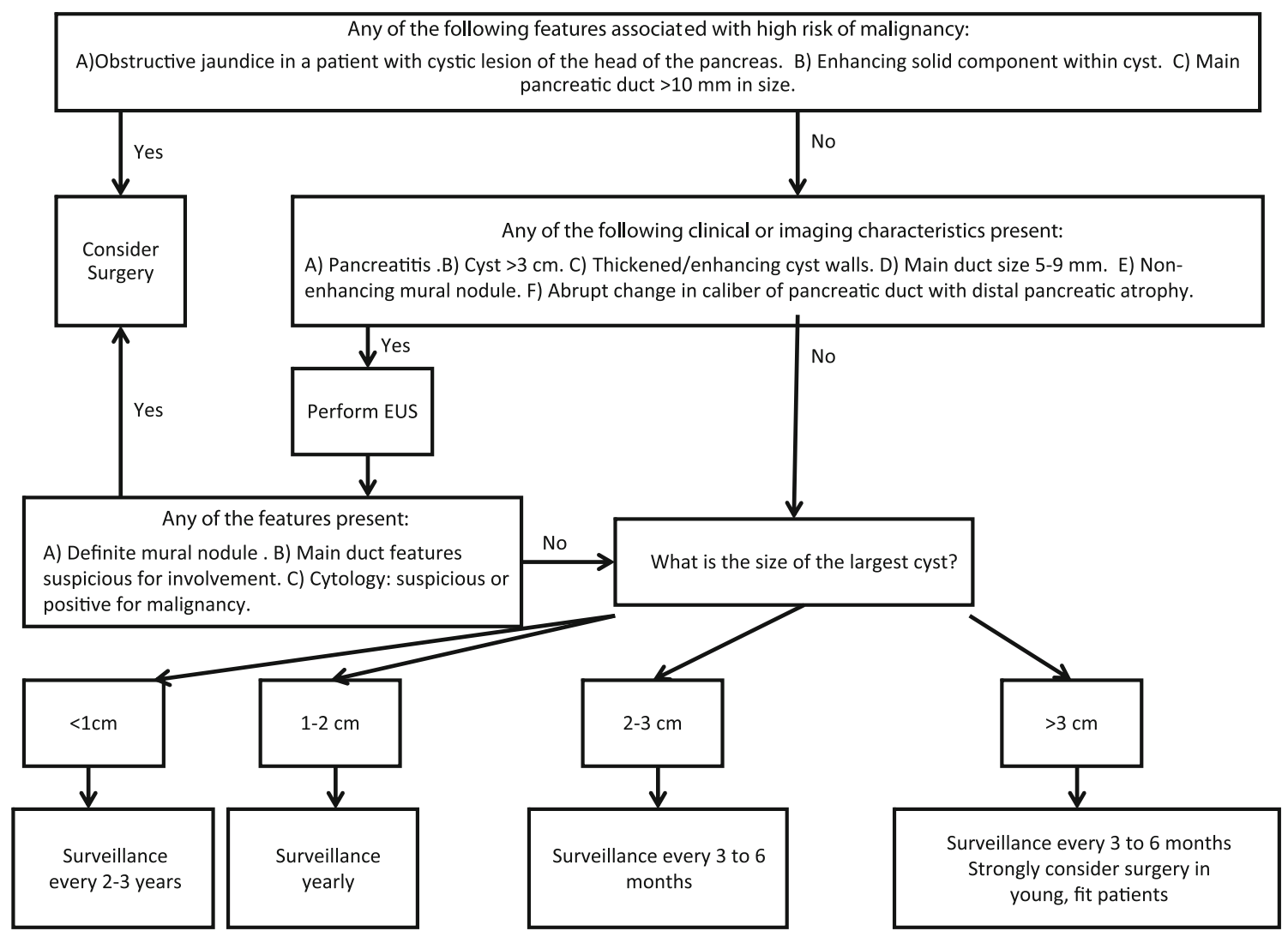

Fig. 4 Management of IPMN (Adapted from Tanaka et al, ${ }^{6}$ )

surveillance is normally performed with cross-sectional imaging every 6 months for 2 years and then annually for a total of 5 years.

\section{Cystic Neuroendocrine Neoplasms}

Similar to their solid counterpart, cystic NEN are considered to be malignant lesions and should undergo complete surgical resection. The role of enucleation of non-insulinoma neuroendocrine neoplasms is controversial and should be avoided. The outcome for cystic NEN is good with a 5-year survival rate of $98 \%$ similar to solid neuroendocrine neoplasm. ${ }^{5}$

\section{Non-surgical Treatment}

The majority of patients presenting with pancreatic cysts are elderly. Pancreaticoduodenectomy is associated with a mortality of up to $2 \%$, with morbidity of approximately $40 \%$ even in high volume centers. ${ }^{20,32,33}$ Furthermore, there is significant cost in performing surveillance of cysts over several years. Given these factors, non-operative therapies for pancreatic cysts have been proposed. Ablation of the epithelial lining of pancreatic cysts has been proposed as a way to remove the neoplastic potential. To date, there have been five studies using either ethanol alone or with paclitaxel for cyst ablation. ${ }^{34-38}$ Cyst have decreased to $<5 \%$ of their original size following ablation in 33 to $35 \%$ of patients treated with ethanol ${ }^{34,37}$ and 50 to $79 \%$ using combination alcohol and paclitaxel, ${ }^{35,36,38}$ with increased ablation when more than one ablation session is performed. ${ }^{39}$ In patients who have undergone surgical resection, cyst epithelial ablation varies from 0 to $100 \%$. Complications from this procedure are higher than those reported with routine EUS-FNA of a pancreatic cyst, with postprocedure pancreatitis occurring in between 2 and $10 \%$ of patients, abdominal pain in $2 \%$ to $20 \%$, fever in $2 \%$, and intracystic bleeding in $2 \%{ }^{34-38}$ Cyst ablation is an interesting concept, but given the lack of complete ablation of the epithelium, it should only be performed in individuals who are not surgical candidates and should be performed as part of a clinical trial.

\section{Conclusion}

Pancreatic cysts are being detected with increased frequency. Improvements have been made over the last decade, with fewer benign cysts undergoing surgical resection; however, further progress is required. Current tools for differentiating mucinous from non-mucinous cysts are inadequate. New markers show promise but require validation in large, prospective trials. 


\section{References}

1. Ikeda M, Sato T, Morozumi A, Fujino MA, Yoda Y, Ochiai M, et al. Morphologic changes in the pancreas detected by screening ultrasonography in a mass survey, with special reference to main duct dilatation, cyst formation, and calcification. Pancreas. 1994;9 (4):508-12. Epub 1994/07/01.

2. Laffan TA, Horton KM, Klein AP, Berlanstein B, Siegelman SS, Kawamoto S, et al. Prevalence of unsuspected pancreatic cysts on MDCT. AJR American journal of roentgenology. 2008;191 (3):802-7. Epub 2008/08/22.

3. de Jong K, Nio CY, Hermans JJ, Dijkgraaf MG, Gouma DJ, van Eijck $\mathrm{CH}$, et al. High prevalence of pancreatic cysts detected by screening magnetic resonance imaging examinations. Clinical gastroenterology and hepatology: the official clinical practice journal of the American Gastroenterological Association. 2010;8(9):80611. Epub 2010/07/14.

4. Lee KS, Sekhar A, Rofsky NM, Pedrosa I. Prevalence of incidental pancreatic cysts in the adult population on MR imaging. The American journal of gastroenterology. 2010;105(9):2079-84. Epub 2010/04/01

5. Valsangkar N, Morales-Oyarvide V, Thayer S, Ferrone C, Wargo J, Warshaw A, et al. 851 resected cystic tumors of the pancreas: A 33-year experience at the Massachusetts General Hospital. Surgery. 2012;Epub ahead of print.

6. Tanaka M, Fernandez-Del Castillo C, Adsay V, Chari S, Falconi M, Jang JY, et al. International consensus guidelines 2012 for the management of IPMN and MCN of the pancreas. Pancreatology. 2012;12(3):183-97. Epub 2012/06/13.

7. Reddy RP, Smyrk TC, Zapiach M, Levy MJ, Pearson RK, Clain JE, et al. Pancreatic mucinous cystic neoplasm defined by ovarian stroma: demographics, clinical features, and prevalence of cancer. Clinical gastroenterology and hepatology: the official clinical practice journal of the American Gastroenterological Association. 2004;2(11):1026-31. Epub 2004/11/20.

8. Kimura W, Moriya T, Hanada K, Abe H, Yanagisawa A, Fukushima $\mathrm{N}$, et al. Multicenter study of serous cystic neoplasm of the Japan pancreas society. Pancreas. 2012;41(3):380-7. Epub 2012/03/15.

9. Crippa S, Salvia R, Warshaw AL, Dominguez I, Bassi C, Falconi $\mathrm{M}$, et al. Mucinous cystic neoplasm of the pancreas is not an aggressive entity: lessons from 163 resected patients. Annals of surgery. 2008;247(4):571-9. Epub 2008/03/26.

10. Yamao K, Yanagisawa A, Takahashi K, Kimura W, Doi R, Fukushima N, et al. Clinicopathological features and prognosis of mucinous cystic neoplasm with ovarian-type stroma: a multiinstitutional study of the Japan pancreas society. Pancreas. 2011;40 (1):67-71. Epub 2010/10/07.

11. Khashab MA, Shin EJ, Amateau S, Canto MI, Hruban RH, Fishman EK, et al. Tumor size and location correlate with behavior of pancreatic serous cystic neoplasms. The American journal of gastroenterology. 2011;106(8):1521-6. Epub 2011/04/07.

12. Reddy S, Cameron JL, Scudiere J, Hruban RH, Fishman EK, Ahuja N, et al. Surgical management of solid-pseudopapillary neoplasms of the pancreas (Franz or Hamoudi tumors): a large single-institutional series. Journal of the American College of Surgeons. 2009;208(5):950-7; discussion 7-9. Epub 2009/05/30.

13. Yang F, Fu DL, Jin $\mathrm{C}$, Long J, Yu XJ, Xu J, et al. Clinical experiences of solid pseudopapillary tumors of the pancreas in China. Journal of gastroenterology and hepatology. 2008;23 (12):1847-51. Epub 2008/08/30.

14. Papavramidis T, Papavramidis S. Solid pseudopapillary tumors of the pancreas: review of 718 patients reported in English literature. Journal of the American College of Surgeons. 2005;200(6):96572. Epub 2005/06/01.
15. Malleo G, Bassi C, Rossini R, Manfredi R, Butturini G, Massignani $\mathrm{M}$, et al. Growth pattern of serous cystic neoplasms of the pancreas: observational study with long-term magnetic resonance surveillance and recommendations for treatment. Gut. 2012;61(5):746-51. Epub 2011/09/24.

16. Sahani DV, Kadavigere R, Saokar A, Fernandez-del Castillo C, Brugge WR, Hahn PF. Cystic pancreatic lesions: a simple imagingbased classification system for guiding management. Radiographics: a review publication of the Radiological Society of North America, Inc. 2005;25(6):1471-84. Epub 2005/11/15.

17. Brugge WR, Lewandrowski K, Lee-Lewandrowski E, Centeno BA, Szydlo T, Regan S, et al. Diagnosis of pancreatic cystic neoplasms: a report of the cooperative pancreatic cyst study. Gastroenterology. 2004;126(5):1330-6. Epub 2004/05/08.

18. van der Waaij LA, van Dullemen HM, Porte RJ. Cyst fluid analysis in the differential diagnosis of pancreatic cystic lesions: a pooled analysis. Gastrointestinal endoscopy. 2005;62(3):383-9. Epub 2005/08/23.

19. Frossard JL, Amouyal P, Amouyal G, Palazzo L, Amaris J, Soldan $\mathrm{M}$, et al. Performance of endosonography-guided fine needle aspiration and biopsy in the diagnosis of pancreatic cystic lesions. The American journal of gastroenterology. 2003;98(7):1516-24. Epub 2003/07/23.

20. Galanis C, Zamani A, Cameron JL, Campbell KA, Lillemoe KD, Caparrelli D, et al. Resected serous cystic neoplasms of the pancreas: a review of 158 patients with recommendations for treatment. Journal of gastrointestinal surgery: official journal of the Society for Surgery of the Alimentary Tract. 2007;11(7):820-6. Epub 2007/04/19

21. Tseng JF, Warshaw AL, Sahani DV, Lauwers GY, Rattner DW, Fernandez-del Castillo C. Serous cystadenoma of the pancreas: tumor growth rates and recommendations for treatment. Annals of surgery. 2005;242(3):413-9; discussion 9-21. Epub 2005/09/02.

22. Khalid A, Brugge W. ACG practice guidelines for the diagnosis and management of neoplastic pancreatic cysts. The American journal of gastroenterology. 2007;102(10):2339-49. Epub 2007/ $09 / 04$.

23. Kimura W, Makuuchi M. Operative indications for cystic lesions of the pancreas with malignant potential-our experience. Hepatogastroenterology. 1999;46(25):483-91. Epub 1999/05/06.

24. Kang MJ, Jang JY, Kim SJ, Lee KB, Ryu JK, Kim YT, et al. Cyst growth rate predicts malignancy in patients with branch duct intraductal papillary mucinous neoplasms. Clinical gastroenterology and hepatology: the official clinical practice journal of the American Gastroenterological Association. 2011;9(1):87-93. Epub 2010/ $09 / 21$.

25. Levy P, Jouannaud V, O'Toole D, Couvelard A, Vullierme MP, Palazzo L, et al. Natural history of intraductal papillary mucinous tumors of the pancreas: actuarial risk of malignancy. Clinical gastroenterology and hepatology: the official clinical practice journal of the American Gastroenterological Association. 2006;4 (4):460-8. Epub 2006/04/18.

26. Kosmahl M, Pauser U, Peters K, Sipos B, Luttges J, Kremer B, et al. Cystic neoplasms of the pancreas and tumor-like lesions with cystic features: a review of 418 cases and a classification proposal. Virchows Archiv: an international journal of pathology. 2004;445 (2):168-78. Epub 2004/06/09.

27. Warshaw AL, Compton CC, Lewandrowski K, Cardenosa G, Mueller PR. Cystic tumors of the pancreas. New clinical, radiologic, and pathologic observations in 67 patients. Annals of surgery. 1990;212(4):432-43; discussion 44-5. Epub 1990/10/01.

28. Le Borgne J, de Calan L, Partensky C. Cystadenomas and cystadenocarcinomas of the pancreas: a multiinstitutional retrospective study of 398 cases. French Surgical Association. Annals of surgery. 1999;230(2):152-61. Epub 1999/08/18. 
29. Sarr MG, Carpenter HA, Prabhakar LP, Orchard TF, Hughes S, van Heerden JA, et al. Clinical and pathologic correlation of $84 \mathrm{mu}-$ cinous cystic neoplasms of the pancreas: can one reliably differentiate benign from malignant (or premalignant) neoplasms? Annals of surgery. 2000;231(2):205-12. Epub 2000/02/16.

30. Thompson LD, Becker RC, Przygodzki RM, Adair CF, Heffess CS. Mucinous cystic neoplasm (mucinous cystadenocarcinoma of low-grade malignant potential) of the pancreas: a clinicopathologic study of 130 cases. The American journal of surgical pathology. 1999;23(1):1-16. Epub 1999/01/15.

31. Horisawa M, Niinomi N, Sato T, Yokoi S, Oda K, Ichikawa M, et al. Frantz's tumor (solid and cystic tumor of the pancreas) with liver metastasis: successful treatment and long-term follow-up. Journal of pediatric surgery. 1995;30(5):724-6. Epub 1995/05/01.

32. Allen PJ, D'Angelica M, Gonen M, Jaques DP, Coit DG, Jarnagin WR, et al. A selective approach to the resection of cystic lesions of the pancreas: results from 539 consecutive patients. Annals of surgery. 2006;244(4):572-82. Epub 2006/09/26.

33. Goh BK, Tan YM, Cheow PC, Chung YF, Chow PK, Wong WK, et al. Cystic lesions of the pancreas: an appraisal of an aggressive resectional policy adopted at a single institution during 15 years. American journal of surgery. 2006;192(2):148-54. Epub 2006/07/25.
34. Gan SI, Thompson CC, Lauwers GY, Bounds BC, Brugge WR. Ethanol lavage of pancreatic cystic lesions: initial pilot study. Gastrointestinal endoscopy. 2005;61(6):746-52. Epub 2005/04/28.

35. Oh HC, Seo DW, Lee TY, Kim JY, Lee SS, Lee SK, et al. New treatment for cystic tumors of the pancreas: EUS-guided ethanol lavage with paclitaxel injection. Gastrointestinal endoscopy. 2008;67(4):636-42. Epub 2008/02/12.

36. Oh HC, Seo DW, Kim SC, Yu E, Kim K, Moon SH, et al. Septated cystic tumors of the pancreas: is it possible to treat them by endoscopic ultrasonography-guided intervention? Scandinavian journal of gastroenterology. 2009;44(2):242-7. Epub 2008/10/25.

37. DeWitt J, McGreevy K, Schmidt CM, Brugge WR. EUS-guided ethanol versus saline solution lavage for pancreatic cysts: a randomized, double-blind study. Gastrointestinal endoscopy. 2009;70 (4):710-23. Epub 2009/07/07.

38. Oh HC, Seo DW, Song TJ, Moon SH, Park do H, Soo Lee S, et al. Endoscopic ultrasonography-guided ethanol lavage with paclitaxel injection treats patients with pancreatic cysts. Gastroenterology. 2011;140(1):172-9. Epub 2010/10/19.

39. DiMaio CJ, DeWitt JM, Brugge WR. Ablation of pancreatic cystic lesions: the use of multiple endoscopic ultrasound-guided ethanol lavage sessions. Pancreas. 2011; 40(5):664-8. Epub 2011/05/13. 